\title{
Effect of stress-induced grain growth during room temperature tensile deformation on ductility in nanocrystalline metals
}

\author{
WEICHANG XU, PINQIANG DAI* and XIAOLEI WU ${ }^{\dagger}$ \\ College of Materials Science and Engineering, Fuzhou University, Fuzhou 350108, China \\ ${ }^{\dagger}$ State Key Laboratory of Nonlinear Mechanics, Institute of Mechanics, Chinese Academy of Sciences, \\ Beijing 100080, China
}

MS received 24 March 2009; revised 17 April 2009

\begin{abstract}
In the present study defect-free nanocrystalline (nc) Ni-Co alloys with the Co content ranging from $2 \cdot 4-59 \cdot 3 \%$ (wt. \%) were prepared by pulse electrodeposition. X-ray diffraction analysis shows that only a single face-centred cubic solid solution is formed for each alloy and that the grain size reduces monotonically with increasing Co content, which is consistent with transmission electron microscopy (TEM) observations. In the nc Ni-Co alloys, both the ultimate tensile strength and the elongation to failure increase as the Co content increases. The TEM observations reveal that stress-induced grain growth during tensile deformation is significantly suppressed for the nc Ni-Co alloys rich in $\mathrm{Co}$ in sharp contrast to those poor in Co. We believe that sufficient solutes could effectively pin grain boundaries making grain boundary motions (e.g. grain boundary migration and/or grain rotation) during deformation more difficult. Thus, stress-induced grain growth is greatly suppressed. At the same time, shear banding plasticity instability is correspondingly delayed leading to the enhanced ductility.
\end{abstract}

Keywords. Nanocrystalline; Ni-Co; mechanical property; ductility; grain growth.

\section{Introduction}

Nanocrystalline (nc) metals, with very high strength in contrast to their coarse-grained counterparts, will have extensive engineering applications in the future as adequate ductility is developed. In the past decade, plentiful investigations have been carried out with the objective of finding several proper routes to enhance the low ductility of nc metals. Ultrahigh strength combined with good ductility has been shown in some nc metals (Karimpoor et al 2003; Li and Ebrahimi 2004; Gu et al 2006; Guduru et al 2007; Wei et al 2007). The improved ductility is mostly ascribed to enhancement of strain hardening which can suppress or delay plasticity instability in the process of plastic deformation (Wang et al 2002; Li and Ebrahimi 2004; Ma 2006).

For nc metals, shear banding is a common type of plasticity instability. Shear bands are frequently observed on the surface of specimen, especially for the thin-sheet tensile specimen, as plasticity instability occurs in the deformation process (Dalla Torre et al 2002; Wei et al 2002; Misra et al 2005). Inside the shear band, severely deformed microstructures such as elongated grains and grown grains are observed, while the grains in the exte-

\footnotetext{
*Author for correspondence (pqdai@126.com)
}

rior of the shear band show a relatively small change in the grain size and shape (Wei et al 2002). Thus, we deduce that the shear bands caused by localized deformation might initially occur in the regions, where nanograins are experiencing fast growth driven by applied stresses. In recent years, the propensity of stress-induced grain growth in nc metals is well established by molecular dynamics (MD) simulations (Haslam et al 2003; Schiøtz 2004; Farkas et al 2006, 2008) and experimental studies (Shan et al 2004; Zhang et al 2004; Fan et al 2006a; Liao et al 2006; Pan et al 2006; Brandstetter et al 2008; Wang et al 2008). Based on the above facts, we are stimulated to consider such an issue: whether the extent of grain growth during room temperature $(R T)$ tensile deformation affects the ductility, since fast grain growth driven by applied stresses could result in ultimate shear banding plasticity instability.

In the present study, a series of $\mathrm{nc} \mathrm{Ni-Co}$ alloys with varying compositions were prepared by electrodeposition. First, the nc Ni-Co alloys were testified to be free of defects by tensile tests. Then, transmission electron microscope (TEM) observations were carried out using the as-deposited samples and the correspondingly as-deformed samples (from tensile failures) to compare the significance of grain growth during tensile deformation. On this basis, the relationship between the extent of grain growth during tensile deformation and the resulting ductility was investigated. 


\section{Experimental}

\subsection{Fabrication method}

In the present study an aqueous sulfamate-based electrolyte was used to produce nc Ni-Co alloys by square-wave pulse electrodeposition. The electrolyte was made of $1.65 \pm 0.01 \mathrm{M} / \mathrm{L}$ the sum of $\left[\mathrm{Ni}^{2+}\right]$ and $\left[\mathrm{Co}^{2+}\right]$ (nickel sulfamate and cobalt sulfamate as nickel source and cobalt source, respectively), $20 \mathrm{~g} / \mathrm{L} \mathrm{NiCl} 2 \cdot 6 \mathrm{H}_{2} \mathrm{O}, 30 \mathrm{~g} / \mathrm{L}$ boric acid, $2.5 \mathrm{~g} / \mathrm{L}$ soluble saccharin and $0.1 \mathrm{~g} / \mathrm{L}$ lauryl sodium sulfate. Ni-Co alloys with varying compositions were obtained by only changing the $\mathrm{Ni} / \mathrm{Co}$ ion ratio in the electrolyte with invariable other electrodeposition conditions. The main electrodeposition conditions are listed in table 1. Under these conditions, Ni-Co alloys, whose thickness was $180-200 \mu \mathrm{m}$, were deposited on stainless steel substrates, which had been polished to a mirror-like finish surface prior to electrodeposition. After electrodeposition, alloy deposits can be mechanically stripped from stainless steels.

\subsection{Composition determination and microstructure characterization}

The compositions of nc Ni-Co alloys were determined by the energy dispersive X-ray (EDX) spectroscopy method with a scanned area of $3 \times 3 \mathrm{~mm}^{2}$. The composition unit is the weight percent (wt.\%). The crystallographic structure of the as-deposited nc Ni-Co alloys were analysed by X-ray diffraction (XRD). XRD was carried out on a Philip X'Pert Pro MPP X-ray diffractometer using $\mathrm{Cu}-\mathrm{K} \alpha$ radiation at an acceleration voltage of $45 \mathrm{keV}$ and a current of $40 \mathrm{~mA}$. In addition, the grain size was quantified by applying the integral breadth method to the $\{111\}$ family of peaks (Zhang et al 2003). The microstructures of nc Ni-Co alloys were observed by TEM. TEM observations were performed using a Tecnai G2 F20 S-TWIN operated at $200 \mathrm{kV}$. TEM samples were prepared by

Table 1. Operating conditions of electrodeposition for producing nc Ni-Co alloys

\begin{tabular}{lc}
\hline Parameters & \\
\hline Electrolyte volume $(\mathrm{L})$ & 1 \\
Electrolyte temperature $\left({ }^{\circ} \mathrm{C}\right)$ & 60 \\
$\mathrm{pH}$ & 3 \\
Average current density $\left(\mathrm{A} / \mathrm{dm}^{2}\right)$ & 10 \\
On-time in a cycle $(\mathrm{ms})$ & 50 \\
Duty ratio $(\%)$ & 50 \\
Anode material & Electrolytic Ni \\
& $\quad$ (purity $>99.9$ mass.\%) \\
Ratio of cathode area to anode & $1: 4$ \\
$\quad$ area in the plating bath & Stainless steel sheet \\
Cathode substrate & $(1 \mathrm{Cr} 15 \mathrm{Mn} 8 \mathrm{Ni5Cu} 2)$ \\
\end{tabular}

double-jet electropolishing using an electrolyte consisting of $5 \%$ (volume) perchloric acid and $95 \%$ (volume) ethanol at a temperature below $-20^{\circ} \mathrm{C}$. The TEM average grain size was determined from dark field TEM images using image analysis software (Photoshop 7.0) to count at least 300 grains for each sample.

\subsection{Mechanical properties test and fracture analysis}

Dog-bone-shaped tensile specimens with a gauge length of $10 \mathrm{~mm}$ and a gauge width of $3 \mathrm{~mm}$ were cut using an electro-discharging machine. Tensile tests were carried out on a CMT-6104 test machine at $R T$ and a strain rate of $10^{-3} \mathrm{~s}^{-1}$. The tensile ductility in this study was measured through the gripping-head movement of the tensile machine. A XL30 ESEM-TMP environmental scanning electron microscopy (SEM) was employed to analyse fractured samples.

\section{Results and discussion}

\subsection{Microstructure analysis}

XRD patterns for specimens with compositions ranging from $2 \cdot 4-59 \cdot 3 \%$ Co are shown in figure 1 . Several trends can be observed as the Co content increases. First, the crystal structure is unchanged with compositions. All of the peaks can be indexed with face-centred cubic $(f c c)$ reflections, as expected for $\gamma$ solid solutions. Second, the addition of Co clearly leads to substantial peak broadening, which is quantified through the trend of decreasing

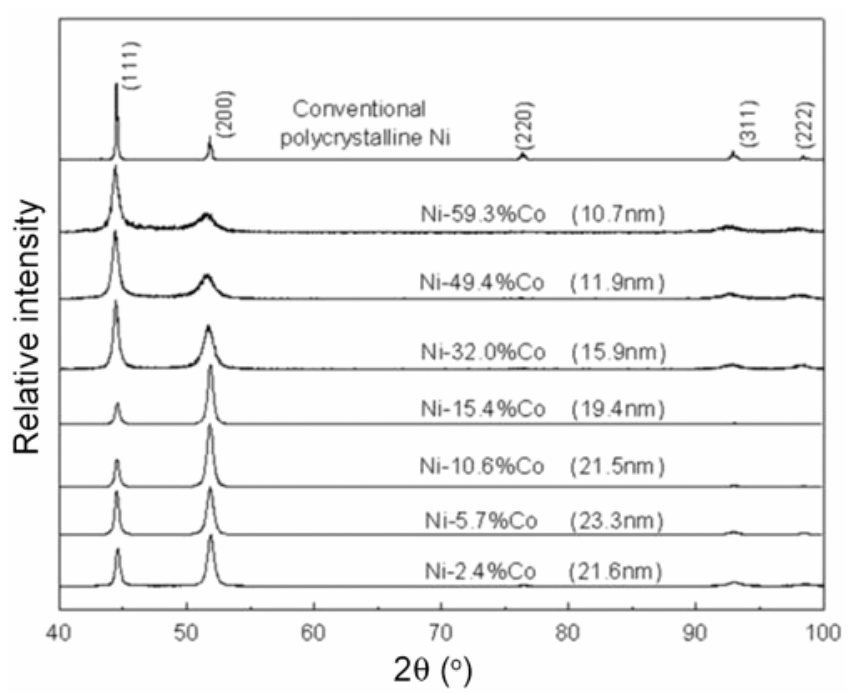

Figure 1. XRD patterns for specimens with global Co content from $2 \cdot 4-59 \cdot 3 \%$. The XRD grain size calculated using the integral breadth method is also shown for each specimen. Also shown for comparison is the XRD pattern for conventional polycrystalline Ni powder. 

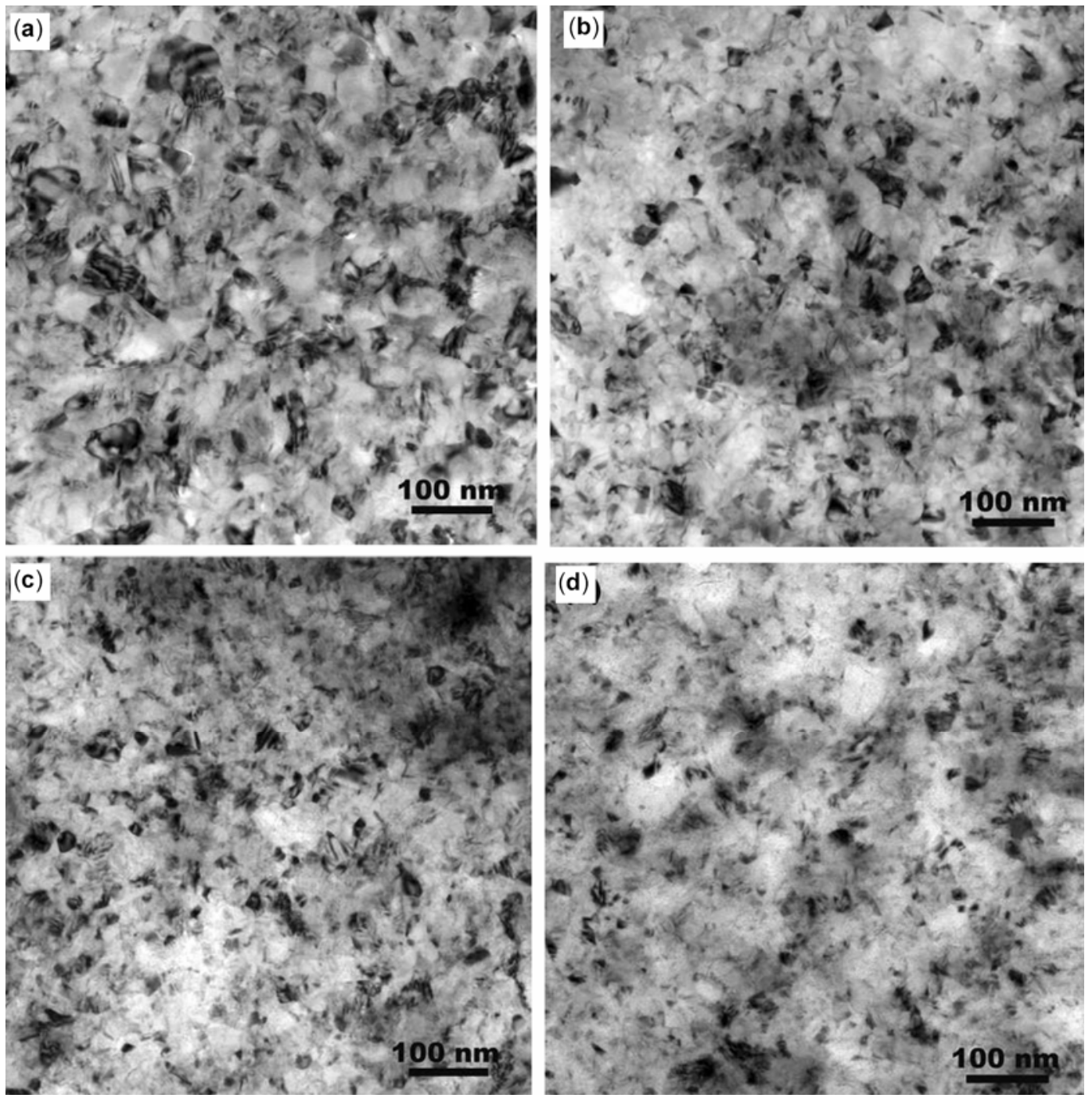

Figure 2. TEM bright field images of the as-deposited (a) $\mathrm{Ni}-2 \cdot 4 \% \mathrm{Co}$, (b) $\mathrm{Ni}-15 \cdot 4 \% \mathrm{Co}$, (c) $\mathrm{Ni}-32 \cdot 0 \% \mathrm{Co}$ and (d) $\mathrm{Ni}-59 \cdot 3 \% \mathrm{Co}$.

grain size reported in figure 1 . The present electrodeposited Ni-Co alloys show the strong composition dependency of grain size, which is shared by other electrodeposited Ni-based binary systems, such as Ni-P (Jeong et al 2003), $\mathrm{Ni}-\mathrm{W}$ (Cheung et al 1994) and $\mathrm{Ni}-\mathrm{Fe}$ (Li and Ebrahimi 2003). The XRD average grain sizes show the maximum average grain size as $21.6 \mathrm{~nm}$ for the $\mathrm{Ni}-2 \cdot 4 \% \mathrm{Co}$ alloy and the minimum average grain size as $10 \cdot 7 \mathrm{~nm}$ for the $\mathrm{Ni}-59 \cdot 3 \% \mathrm{Co}$ alloy. Finally, it seems that when the grain size is small enough (e.g. $10 \cdot 7 \mathrm{~nm})$, the nc $\mathrm{Ni}-\mathrm{Co}$ alloys tend to gain weak textures close to those of conventional polycrystalline $\mathrm{Ni}$ powder free of textures, as shown at the top of figure 1 .

In order to verify the grain sizes determined by XRD, direct observations of the alloy nanostructure were also conducted by TEM for representative specimens containing $2 \cdot 4,15 \cdot 4,32.0$ and $59.3 \%$ Co. Bright field images for these specimens are shown in figure 2 . The TEM average grain sizes for each specimen are 24.2, 21.6, 17.3 and $14.3 \mathrm{~nm}$ for the alloys with $2 \cdot 4,15 \cdot 4,32.0$ and $59 \cdot 3 \% \mathrm{Co}$, respectively. These values are in line with those approximated by the XRD line broadening measurements which gave the average grain size $\approx 21.6,19.4,15.9$ and $10.7 \mathrm{~nm}$ for specimens of similar respective compositions. Together, a series of micrographs in figure 2 illustrate the same trend suggested by figure 1 that a clear refinement of the nanostructure occurs with increasing Co content.

\subsection{Mechanical properties}

Figure 3 shows a typical tensile engineering stress-strain curve for each composition, respectively. At least three tensile specimens were tested for each composition. All of these curves show similar characteristics to those reported in defect-free specimens (Karimpoor et al 2003; 
Li and Ebrahimi 2004; Gu et al 2006; Wei et al 2007). Furthermore, each specimen shows an edge fracture with an angle of $\sim 55^{\circ}$ with respect to the tensile direction.

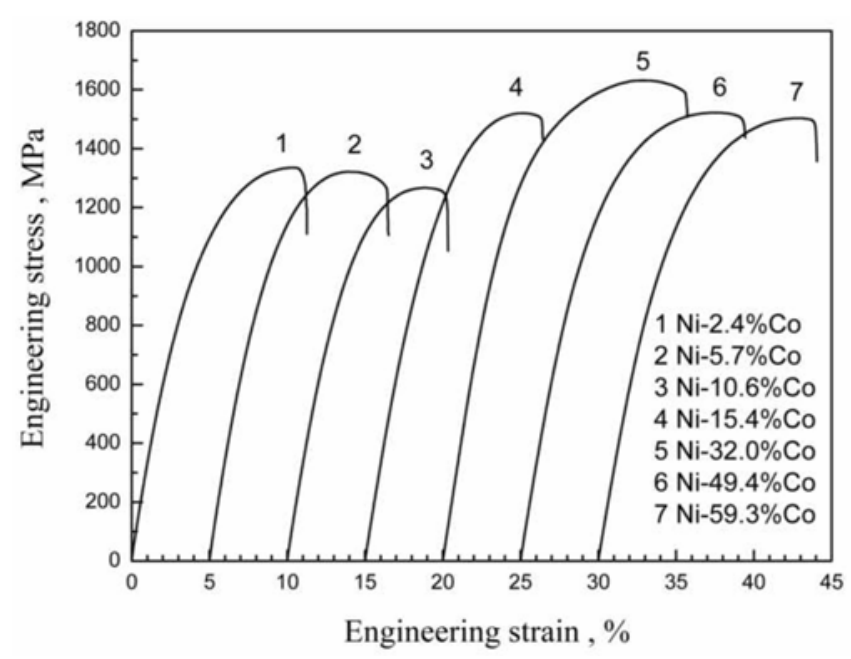

Figure 3. Tensile engineering stress-strain curves for nc $\mathrm{Ni}-\mathrm{Co}$ alloys.
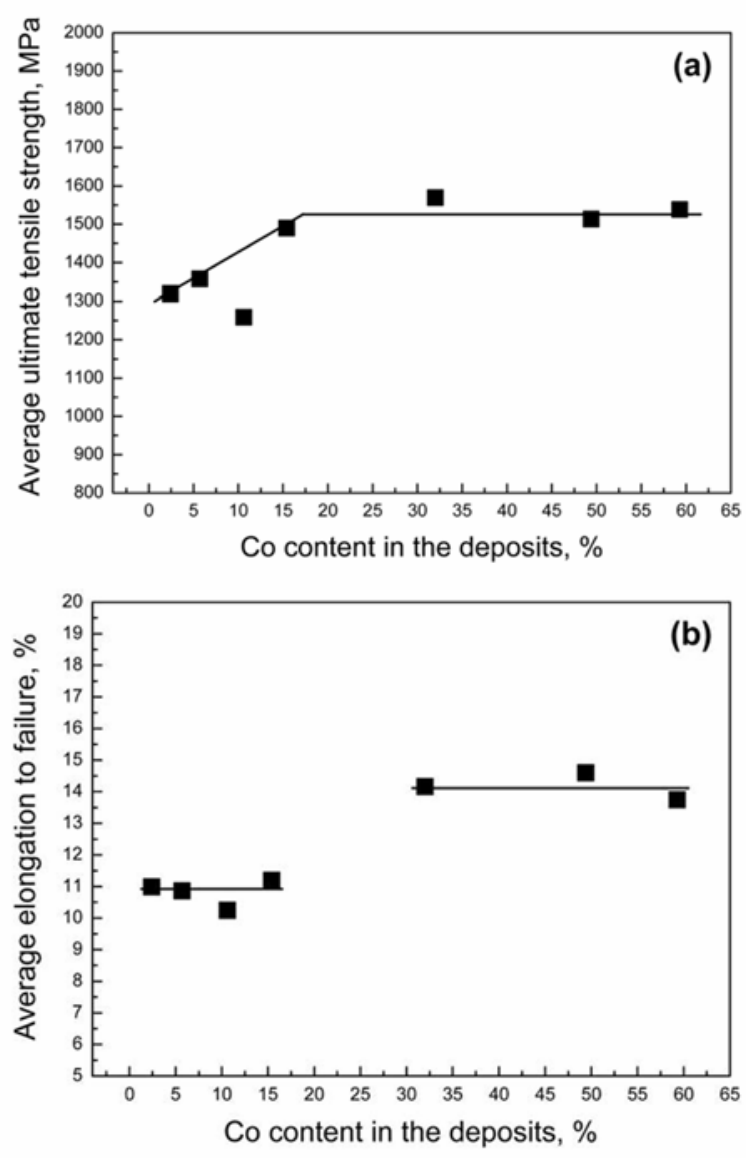

Figure 4. (a) Average ultimate tensile strength vs Co content and (b) average elongation to failure vs Co content for nc $\mathrm{Ni}-\mathrm{Co}$ alloys.
According to the stress-strain curves, the average ultimate tensile strength (UTS) and the average elongation to failure (ETF) vs the Co content, respectively are plotted in figures 4(a) and (b).

Figure 4(a) shows the curve of average UTS vs Co content. There is an apparent increase in the average UTS from $1300-1500 \mathrm{MPa}$, as the Co content is increased from $2 \cdot 4-15 \cdot 4 \%$. When the Co content exceeds $15 \cdot 4 \%$, in the range of $32 \cdot 0-59 \cdot 3 \%$, the average UTS ceases to increase and maintains at about $1550 \mathrm{MPa}$. According to the results in a Ni-Fe system ( $\mathrm{Li}$ and Ebrahimi 2003) and the fact that Co $(0.167 \mathrm{~nm})$ has the most similar atomic radius to that of $\mathrm{Ni}(0 \cdot 162 \mathrm{~nm})$, we believe solid solution strengthening from the Co addition to $\mathrm{Ni}$ is very weak compared with strengthening by grain refinement.

In addition, Co is a well known element with a low stacking fault energy (SFE) and the SFE in Ni-Co alloys decreases with increasing Co content (Zhou et al 2001). Furthermore, the reduction of SFE in nc alloys has been evidenced to improve the strength by facilitating the activities of partial dislocations (Ebrahimi et al 2004). Therefore, when the Co content is in the range of $2 \cdot 4-15.4 \%$, the increase in the average UTS could be mainly caused by a reduction in the SFE instead of grain refinement due to the small variation in the grain size, e.g. $21 \pm 1 \mathrm{~nm}$.

When the Co content is increased to $59.3 \%$, the grain size is reduced to $10.7 \mathrm{~nm}$. The reduction of SFE and grain refinement should have significantly increased the strength. But the expectation never happened. Therefore, the additional softening, if it exists, could set off increase in strength from grain refinement and a reduction in SFE. This strength softening is likely to be caused by grain boundary (GB) sliding dominated deformation, which results in the inverse Hall-Petch effect (Schiøtz 2003; Farkas and Curtin 2005).

The curve of average ETF vs Co content is shown in figure 4(b). When the Co content is in the range of 2.4$15.4 \%$, the average ETF maintains at about $11 \%$. Increasing the Co content in this range has a small effect on the ductility. However, when the Co content is increased to $32.0 \%$, the average ETF is enhanced to about $14 \%$ and maintains at this high level with further increasing Co content to $59 \cdot 3 \%$. This indicates that the Ni-Co alloys rich in Co have the combination of high strength with enhanced ductility.

\subsection{Fracture analysis}

The SEM images of tensile fractured surface for representative specimens containing $2 \cdot 4,15 \cdot 4,32 \cdot 0$ and $59 \cdot 3 \%$ Co are shown in figure 5. An apparent transition from deep dimples to shallow dimples was observed with an increase in the Co content. The deep dimples are common fracture morphologies for nc metals with the grain size above $20 \mathrm{~nm}$ (Dalla Torre et al 2002), where plastic 

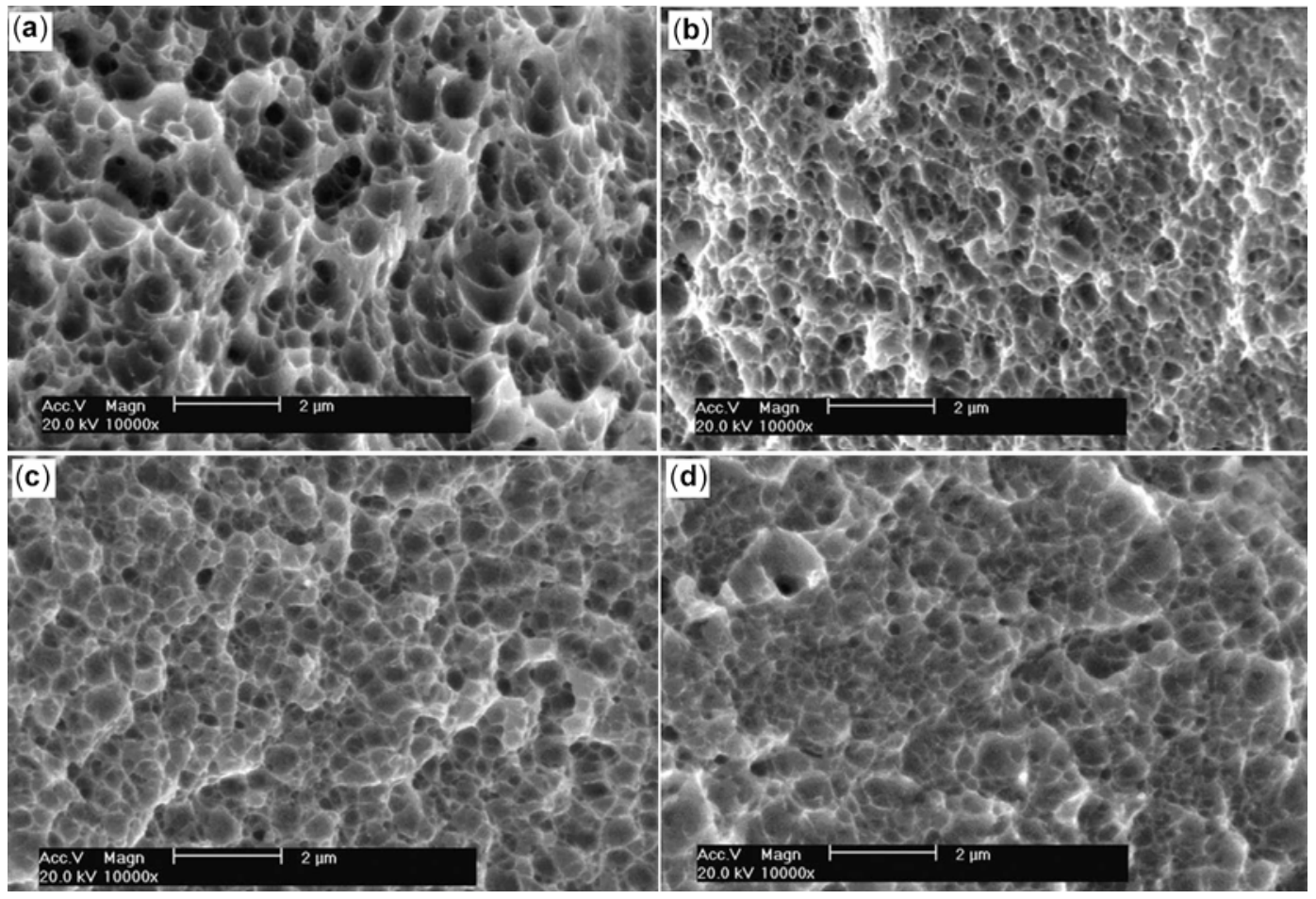

Figure 5. SEM images of tensile fracture surface for (a) $\mathrm{Ni}-2 \cdot 4 \% \mathrm{Co}$, (b) $\mathrm{Ni}-15 \cdot 4 \% \mathrm{Co}$, (c) $\mathrm{Ni}-32 \cdot 0 \%$ $\mathrm{Co}$ and $(\mathbf{d}) \mathrm{Ni}-59 \cdot 3 \% \mathrm{Co}$

deformation is mediated by dislocation motion. The similar shallow dimples were observed in the fracture surface of a nc Ni-Fe alloy (Li and Ebrahimi 2004). They correlated this fractography to a characteristic caused by the GB sliding dominated process. Consequently, we believe that a transition of deformation mechanism from the dislocation dominated process to the GB sliding dominated process occurs in the present $\mathrm{Ni}-\mathrm{Co}$ alloys.

\subsection{Post-deformed microstructure}

Figure 6 shows post-deformed TEM microstructures of representative specimens containing $2 \cdot 4,15.4$ and $59 \cdot 3 \%$ Co. The TEM specimens were sampled in the vicinity of tensile fractures. For the $\mathrm{Ni}-2 \cdot 4 \% \mathrm{Co}$ alloy, the average TEM grain size is $24.2 \mathrm{~nm}$ in the as-deposited state, but the global grain size with about $50 \mathrm{~nm}$ is seen after tension to failure, as observed in figure 6(a). The significant grain growth occurs in most grains just like uniform grain growth. Similar results were obtained in $\mathrm{nc} \mathrm{Ni}$ with a grain size of $\sim 20 \mathrm{~nm}$ (Wang et al 2008). For the postdeformed $\mathrm{Ni}-15 \cdot 4 \% \mathrm{Co}$ alloy (figure 6(b)), the global stress-induced grain growth is alleviated in contrast to the observation in the post-deformed $\mathrm{Ni}-2 \cdot 4 \% \mathrm{Co}$ alloy. A number of large grains with sizes of $60-80 \mathrm{~nm}$, which exceeds the upper bound grain size $(\sim 50 \mathrm{~nm})$ in the as-deposited state, are observed in figure 6(b). However, abnormal grain growth with some grain sizes beyond $250 \mathrm{~nm}$, which was observed in a nc Ni-Fe alloy (Fan et al 2006a), are not observed in the present deformed $\mathrm{Ni}-$ $15.4 \% \mathrm{Co}$ alloy. For the post-deformed $\mathrm{Ni}-59 \cdot 3 \% \mathrm{Co}$ alloy, it was observed in figure 6(c) that the global grain coarsening becomes relatively insignificant and grain coarsening is just accumulated in some dispersive areas, where the maximum grain size was just $30-40 \mathrm{~nm}$ equivalent to the upper bound grain size in the as-deposited state. Similar TEM observations were reported in a $\mathrm{Co}-\mathrm{P}$ alloy (Fan et al 2006b) and nc Co (Zhang and Jia 2006). It seems that stress-induced grain growth is relatively insignificant for nc Co-based metals. For the present nc $\mathrm{Ni}-\mathrm{Co}$ alloys, a transition from global grain growth to local grain coalescence is clearly observed as the Co content increases. Correlating the extent of stress-induced grain growth with ductility (see figure 4(b)), it is revealed that suppression of grain growth during tensile deformation can enhance the ductility.

Nanocrystalline metals have a propensity of stressinduced grain growth and this propensity is relatively stronger for nc pure metals, which was well established by plentiful MD simulations (Haslam et al 2003; Schiøtz 2004; Farkas et al 2006a, 2008) and experimental studies (Shan et al 2004; Zhang et al 2004; Fan et al 2006; Liao et al 2006; Pan et al 2006; Brandstetter et al 2008; Wang et al 2008). Moreover, for nc metals stress-induced grain growth seems to be independent of the grain size or the deformation mechanism. For example, for two nc Ni samples with initial grain sizes of 10 and $20 \mathrm{~nm}$ (here for $\mathrm{nc} \mathrm{Ni} 10 \mathrm{~nm}$ is in the grain size region of the GB sliding 

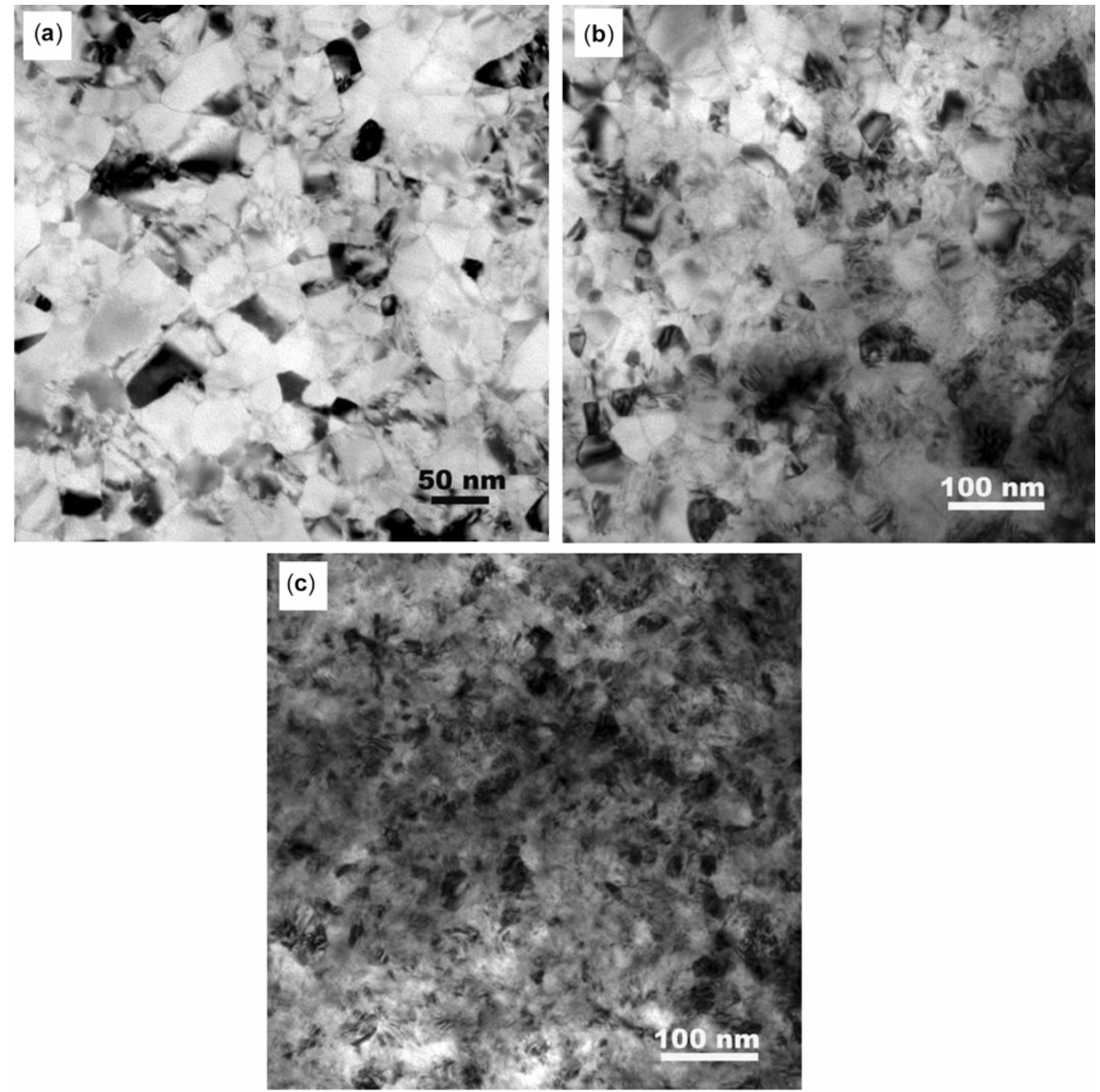

Figure 6. TEM bright field images of tensile fracture of (a) $\mathrm{Ni}-2 \cdot 4 \% \mathrm{Co},(\mathbf{b}) \mathrm{Ni}-15 \cdot 4 \% \mathrm{Co}$ and (c) $\mathrm{Ni}-59 \cdot 3 \% \mathrm{Co}$.

dominated mechanism, while $20 \mathrm{~nm}$ is in the grain size region of the dislocation-mediated mechanisms) (Schiøtz and Jacobsen 2003; Li and Ebrahimi 2004), grain coarsening from the initial grain size to $\sim 80 \mathrm{~nm}$ were both observed in the in situ tensile process of the two samples (Shan et al 2004; Wang et al 2008). Therefore, deformation mechanisms controlled by GB sliding are not expected to facilitate inhabiting stress-induced grain growth.

High strength along with further enhanced ductility is obtained in the present nc Ni-Co alloys with smaller grain sizes $(\sim 10 \mathrm{~nm})$ instead of those with larger grain sizes $(\sim 20 \mathrm{~nm})$. Based on the above discussion, we do not believe that the enhanced ductility is much related to the GB sliding controlled deformation process. The com- parison of grain sizes between as-deposited specimens and post-deformed specimens (see figures 2 and 6) reveals that this enhancement of ductility originated from suppression of stress-induced grain growth during tensile deformation.

The MD simulations of immiscible nc Al-Pb alloy reveals that due to complete segregation of $\mathrm{Pb}$ to $\mathrm{GBs}$, GBs are more stable in the deformation process so that grain growth during deformation is relatively insignificant (Jang et al 2008). Experimentally, Soer et al (2004) also observed that high-angle GBs were pinned effectively during deformation in an ultrafine-grained (ufg) Al-Mg alloy compared to ufg pure $\mathrm{Al}$, making stressinduced grain growth in the $\mathrm{Al}-\mathrm{Mg}$ alloy more difficult 
than in pure Al. It is apparent that for nc and ufg metals solutes in the matrix can help to hinder GB migration in the deformation process. Accordingly, it is reasonable to deem that in the present nc Ni-Co alloys Co solutes play similar role of pinning GBs during deformation and that the pinning effect is strengthened with increasing Co content. As a result, grain growth during tensile deformation is significantly suppressed by adequate Co solutes for the nc Ni-Co alloys with higher Co contents in contrast to those with lower Co contents. As grain growth during tensile deformation is suppressed, the larger uniform deformation can persist and shear banding is delayed leading to the enhanced ductility. In the present study alloying is witnessed to be a useful route to enhance the ductility combined with high strength. However, the effects of the solute states (e.g. species, concentration, and distribution) on GB responses during deformation are not well understood. More investigations in these aspects are expected to be further undertaken.

In addition, the effect of crystallographic textures on stress-induced grain growth should be considered, too. The Ni-Co alloys with very weak textures appear in the region with high Co contents, e.g. $49 \cdot 4 \% \mathrm{Co}$ and $59 \cdot 3 \% \mathrm{Co}$, while a significant texture with preferred $\{200\}$ planes is formed as the Co content is below $32.0 \%$. Individual nanograins tend to align at a preferred orientation under deformation conditions, as a result of an accommodation to plastic deformation (Qin et al 2004). In this case, certain crystallographic textures are created in microstructures of plastically deformed nc metals accompanied by grain coarsening. Grain coalescence by crystallographic orientation accommodation among adjacent grains can be a process of grain rotation (Wang et al 2008) and/or GB migration (Haslam et al 2003; Schiøtz 2004; Farkas et al 2006, 2008). Thus, textures in microstructures would lead to different effects on deformation depending on the direction of applied stresses. The two extreme cases are: if the orientations of original textures are fully favourable for the deformation condition, it would completely promote stress-induced grain growth. On the contrary, it would completely prevent stress-induced grain growth. In the present case, it seems that stronger the $\{200\}$ texture in the $\mathrm{Ni}-\mathrm{Co}$ alloys, the more significant would be the stress-induced grain growth.

\section{Conclusions}

The experimental results on $\mathrm{nc} \mathrm{Ni}-\mathrm{Co}$ alloys are concluded as follows:

(I) A series of defect-free nc Ni-Co alloys with Co content ranging from $2.4-59.3$ wt.\% were prepared by pulse electrodeposition. XRD analysis shows that only a single $f c c$ solid solution is formed for each composition and that the grain size reduces monotonically with increasing Co content. A minimum grain size of $10.7 \mathrm{~nm}$ was obtained for the $\mathrm{Ni}-59 \cdot 3 \% \mathrm{Co}$ alloy.
(II) GB sliding plays a dominant role in the deformation process as grain sizes are close to $\sim 10 \mathrm{~nm}$. Evidence is given by stress-strain curves (e.g. for the $\mathrm{Ni}-\mathrm{Co}$ alloys with $49.4 \%$ and $59.3 \% \mathrm{Co}$, strength softening possibly resulted from GB sliding which sets off strengthening from grain refinement and a reduction in the SFE) and a transition from the tensile fracture morphologies.

(III) The UTS is in the range of 1300-1650 MPa and the EOF in the range of $10 \cdot 5-14.5 \%$. Both the UTS and EOF enhance with increasing Co content.

(IV) TEM observations reveal that grain growth during tensile deformation is significantly suppressed for the alloys with high Co content in contrast to those with low Co content. We believe that grain growth during tensile deformation could be significantly suppressed by sufficient Co solutes pinning GB, independent of deformation mechanisms. Thus, it leads to the enhanced ductility by delaying shear banding plasticity instability.

\section{Acknowledgements}

The present investigation was supported by the Natural Science Foundation of Fujian Province (Grant no. E0810006) and National 863 projects of China (No. 2007AA03Z325).

\section{References}

Brandstetter S, Zhang K, Escuadro A, Weertman J R and Van Swygenhoven H 2008 Scr. Mater. 5861

Cheung C, Palumbo G and Erb U 1994 Scr. Metall. Mater. 31 735

Dalla Torre F, Van Swygenhoven H and Victoria M 2002 Acta Mater. 503957

Ebrahimi F, Ahmed Z and Li H 2004 Appl. Phys. Lett. 853749

Fan G J, Fu L F, Choo H, Liaw P K and Browning N D 2006a Acta Mater. 544781

Fan G J, Fu L F, Qiao D C, Choo H, Liaw P K and Browning N D 2006 b Scr. Mater. 542137

Farkas D and Curtin W A 2005 Mater. Sci. Eng. A412 316

Farkas D, Froeth A and Van Swygenhoven H 2006 Scr. Mater. 55695

Farkas D, Mohanty S and Monk J 2008 Mater. Sci. Eng. $\mathbf{A 4 9 3}$ 33

Gu C D, Lian J S, Jiang Z H and Jiang Q 2006 Scr. Mater. 54 279

Guduru R K, Linga Murty K, Youssef Khaled M, Scattergood R O and Koch C C 2007 Mater. Sci. Eng. A463 14

Haslam A J, Moldovan D, Yamakov V, Wolf D, Phillpot S R and Gleiter H 2003 Acta Mater. 512097

Jang S, Purohit Y, Irving D, Padgett C, Brenner D and Scattergood R O 2008 Mater. Sci. Eng. A493 53

Jeong D H, Erb U, Aust K T and Palumbo G 2003 Scr. Mater. 481067

Karimpoor A A, Erb U, Aust K T and Palumbo G 2003 Scr. Mater. 49651 
Liao X Z, Kilmametov A R, Valiev R Z, Gao H, Li X, Mukherjee A K, Bingert J F and Zhu Y T 2006 Appl. Phys. Lett. 88 021909

Li H and Ebrahimi F 2003 Mater. Sci. Eng. A347 93

Li H and Ebrahimi F 2004 Appl. Phys. Lett. 844307

Ma E 2006 Scr. Mater. 49663

Misra A, Zhang X, Hammon D and Hoagland R G 2005 Acta Mater. 53221

Pan D, Nieh T G and Chen M W 2006 Appl. Phys. Lett. 88 161922

Qin X Y, Zhu X G and Lee J S 2004 Scr. Mater. 50489

Schiøtz J 2004 Mater. Sci. Eng. A375-377 975

Schiøtz J and Jacobsen K W 2003 Science 3011357

Shan Z W, Stach E A, Wiezorek J M K, Knapp J A, Follstaedt D M and Mao S X 2004 Science 305654
Soer W A, De Hosson J Th M, Minor A M, Morris Jr. J W and Stach E A 2004 Acta Mater. 525783

Wang Y B, Li B Q, Sui M L and Mao S X 2008 Appl. Phys. Lett. 92011903

Wei H, Hibbard G D, Palumbo G and Erb U 2007 Scr. Mater. 57996

Wei Q, Jia D, Ramesh K T and Ma E 2002 Appl. Phys. Lett. 81 1240

Zhang K, Weertman J R and Eastman J A 2004 Appl. Phys. Lett. 855197

Zhang X and Jia C 2006 Mater. Sci. Eng. A418 77

Zhang Z, Zhou F and Lavernia E J 2003 Metall. Mater. Trans. A34 1349

Zhou W, Jiang B, Liu Y and Qi X 2001 Trans. Nonferrous Met. Soc. China 11555 